\title{
THE EFFECT OF ISOLATED OR COMBINED SMALL-SIDED GAMES AND SPEED ENDURANCE TRAINING ON PHYSICAL PERFORMANCE PARAMETERS IN YOUNG SOCCER PLAYERS
}

\author{
Erkan Akdoğan', İlker Yılmaz', Yusuf Köklü², Utku Alemdaroğlu², and Ali Onur Cerrah ${ }^{1}$ \\ ${ }^{1}$ Eskişehir Technical University, Faculty of Sport Sciences, Eskişehir, Turkey \\ ${ }^{2}$ Pamukkale University, Faculty of Sport Sciences, Denizli, Turkey
}

Original scientific paper

DOI: $10.26582 / \mathrm{k} \cdot 53.1 .10$

\begin{abstract}
:
The purpose of this study was to investigate the effects of six weeks of small-sided games (SSG), speed endurance (SER) and combined SSG and SER (CT) training programs on sprint, repeated sprint, Yo-Yo intermittent recovery test level 1 (Yo-Yo IR1) and level 2 (Yo-Yo IR2) performance in young soccer players. Forty-one elite young soccer players (body height: $174.0 \pm 7.5 \mathrm{~cm}$, body weight: $59.7 \pm 9.5 \mathrm{~kg}$, age: $14.6 \pm$ 0.5 years, training age: $7.4 \pm 0.6$ years) underwent anthropometric measurements before performing $10 \mathrm{~m}$ and $30 \mathrm{~m}$ sprint tests, repeated sprint tests, and Yo-Yo IR1 and Yo-Yo IR2. The players were then divided into four groups: the SSG group (SSG; $n=11$ ), the SER group (SER; $n=10)$, the CT group $(\mathrm{CT} ; \mathrm{n}=11)$, and the control group (CG; $n=9)$. All groups performed training for six weeks on two days out of the five training days the participants were undertaking. There was a statistically significant increase in the Yo-Yo IR1 and Yo-Yo IR2 test performances of players in SSG, SER and CT groups $(p<.05)$. In addition, players in these groups showed significantly higher percentage increases in Yo-Yo IR2 test performance compared to the CG. The CT group also had a statistically significant increase in Yo-Yo IR1 test performance compared to the CG $(\mathrm{p}<.05)$. In conclusion, while this study shows that SSG and SER training can be used for physical performance development in isolation or in combination, coaches and sports scientists are advised to choose combined training to use training time more efficiently.
\end{abstract}

Key words: football, interval training, game-based training, Yo-Yo intermittent recovery tests

\section{Introduction}

Soccer is an aerobic-based anaerobic sport that includes various movement patterns such as jumping, kicking, challenges, rapid turns, ball control under pressure, running at different speeds, dribbling and tackling (Köklü, Aşçi, Koçak, Alemdaroğlu, \& Dündar, 2011). It has been determined that young soccer players cover a total distance of 6-10 km including $750 \mathrm{~m}$ of high-speed running and they also perform $\sim 250 \mathrm{~m}$ of sprinting and 80 to 155 accelerations during a match (Atan, Foskett, \& Ali, 2016; Harley, et al., 2010; Pettersen \& Brenn, 2019; Rebelo, Brito, Seabra, Oliveira, \& Krustrup, 2014; Vigh-Larsen, Dalgas, \& Andersen, 2018). Therefore, soccer players need to achieve a high level of physical performance in order to ensure a quick recovery after these high-intensity intermittent activities and maintain their performance throughout the match (Bishop \& Spencer, 2004; Harrison, Kilding, Gill, \& Kinugasa, 2014).

Traditionally, most coaches have used running drills without the ball to develop soccer players' physical endurance. However, it has been demonstrated that one can develop physical endurance during the same training session by using smallsided games (SSGs) (Faude, Steffen, Kellmann, \& Meyer, 2014; Hill-Haas, Coutts, Rowsell, \& Dawson, 2009; Impellizzeri, et al., 2006; Los Arcos, et al., 2015). For example, Hill-Hass et al. (2009) showed that both the traditional running drills and SSGs led to comparable gains in the preseason Yo-Yo IR1 test performance in $14.6 \pm 0.9$ year-old players. In another comparative study, Radziminski, Rompa, Barnat, Dargiewicz, and Jastrzebski (2013) found a significant improvement in endurance capacity in the SSG training group compared to the interval training group of $15.0 \pm 0.4$ year-old players, the 8 -week intervention program was applied on two days a week. Finally, in a study comparing interval running training with SSGs, executed by $15.5 \pm$ 0.6 year-old players for eight weeks, Los Arcos et al. (2015) showed that the two training methods caused similar effects in soccer aerobic physical performance. 
Speed endurance training is another training method used to improve players' physical performance. This is a form of high-intensity anaerobic training that can be categorized as speed-endurance production (SEP) and speed-endurance maintenance (SEM) (Ade, Harley, \& Bradley, 2014; Bangsbo, Mohr, \& Krustrup, 2006; Hill-Haas, et al., 2009; Ingebrigtsen, Shalfawi, Tønnessen, Krustrup, \& Holtermann, 2013). Ingebrigtsen et al. (2013) revealed that six weeks of biweekly speed endurance production training sessions significantly improved $10-\mathrm{m}$ sprint performance and the Yo-Yo IR 2 test scores in $16.9 \pm 0.6$-year-old players. The research suggests that speed endurance training enables players to perform high-intensity activities during a match more frequently and for longer durations, and that it reduces recovery time after highintensity activities (Bangsbo, et al., 2006; Iaia, et al., 2009, 2015; Ingebrigtsen, et al., 2013; Rampinini, Impellizzeri, Castagna, Coutts, \& Wisløff, 2009). Studies on the effects of speed endurance training in soccer have shown that 1-3 speed endurance training sessions a week for 2-10 weeks can provide an improvement in repeated sprints (1.9-2.1\%) (Ferrari Bravo, et al., 2008; Thomassen, Christensen, Gunnarsson, Nybo, \& Bangsbo, 2010), maximal aerobic speed (8.1\%) (Dupont, Akakpo, $\&$ Berthoin, 2004), and Yo-Yo IR test performance (22-28\%) (Ferrari Bravo, et al., 2008; Hill-Haas, et al., 2009).

The training effect studies have shown that SSGs and speed endurance training can be used for improving players' physical performance (Hill-Haas, et al., 2009; Ingebrigtsen, et al., 2013). However, few studies have been conducted on the long-term effects of small-sided games and speed endurance training on young soccer players; no studies have investigated the effects of speed endurance training combined with SSGs on players' physical performance. If a combination of speed endurance training and SSGs can enhance players' physical performance within the same training session, coaches will have a chance to use the training time more efficiently. In line with this argument, the purpose of this study was to determine the effects of isolated or combined SSGs and speed endurance (SER) training on sprint, repeated sprint, Yo-Yo IR1 and Yo-Yo IR2 performances in young soccer players. It was hypothesized that the combined SSG and SER training would result in higher training effects on sprint, repeated sprint, Yo-Yo IR1 and Yo-Yo IR2 test performances than the isolated SSG and SER training.

\section{Methods}

\section{Participants}

Forty-one elite young soccer players (body height: $174.0 \pm 7.5 \mathrm{~cm}$, body weight: $59.7 \pm 9.5 \mathrm{~kg}$, age: $14.6 \pm 0.5$ years, training age: $7.4 \pm 0.6$ years) participated voluntarily in this study. The players' physical characteristics are presented in Table 1. All the players who participated in the study were members of the same Turkish club competing in the $\mathrm{U} 15(\mathrm{n}=18)$ and $\mathrm{U16}(\mathrm{n}=23)$ teams of elite academy leagues; they trained for 60-90 minutes five days per week in soccer sessions with their team during their regular training cycle. The team also played four friendly matches during the experimental period. The study was conducted according to the Helsinki Declaration and was approved by the local Ethics Committee. All players gave their written informed consent to participate in the study, and parental approval was also obtained.

\section{Procedures}

The study was completed during a 12-week preseason period. Before the experimental training period, as Radziminski et al. (2013) suggested, all participants completed a comprehensive 4-week aerobic training program consisting of $60-90$ minutes of low intensity activity five days a week to prepare their bodies for anatomic adaptation and to prevent any injuries. After the adaptation period, the anthropometric data of the soccer players were taken (body weight and height), and the players performed sprint tests $(10 \mathrm{~m}$ and $30 \mathrm{~m})$ on the first day. On day two, they underwent repeated sprint ability (RSA) tests $(7 \times 35 \mathrm{~m})$ and on day three, they performed the Yo-Yo Intermittent Recovery Test Level 1 (Yo-Yo IR1). On day five, the Yo-Yo Intermittent Recovery Test Level 2 (Yo-Yo IR2) was administered. After these pretests were completed, the players were divided into four groups based on their scores on the Yo-Yo IR1 test: the small-sided games group (SSG), the speed endurance running

Table 1. Characteristics of the participants (mean $\pm S D$ )

\begin{tabular}{lcccc}
\hline & SSG $(\mathbf{n}=11)$ & CT $(\mathbf{n}=11)$ & SER $(\mathbf{n}=10)$ & CG $(\mathbf{n}=\mathbf{9})$ \\
\hline Age (years) & $14.5 \pm 0.5$ & $14.6 \pm 0.5$ & $14.5 \pm 0.5$ & $14.6 \pm 0.5$ \\
Body height $(\mathrm{cm})$ & $172.6 \pm 9.2$ & $171.4 \pm 7.2$ & $174.5 \pm 6.3$ & $178.3 \pm 5.3$ \\
Body weight $(\mathrm{kg})$ & $55.4 \pm 6.9$ & $58.5 \pm 7.6$ & $60.2 \pm 9.7$ & $66.7 \pm 11.0$ \\
BMI $\left(\mathrm{kg} / \mathrm{m}^{2}\right)$ & $18.6 \pm 1.4$ & $19.6 \pm 1.9$ & $19.9 \pm 2.5$ & $20.9 \pm 2.4$ \\
Training age (years) & $7.3 \pm 0.6$ & $7.5 \pm 0.7$ & $7.2 \pm 0.6$ & $7.7 \pm 0.5$ \\
\hline
\end{tabular}


group (SER), the combined training group (CT: small-sided games + speed endurance running) and the control group (CG). The experimental groups followed the respective training program two days a week (on Tuesdays and Thursdays) during the experimental period. The CG pursued a lowintensity technical and tactical training. All groups participated in the 25-minute warm-up (low-intensity running, dynamic stretching and short passing) and 10-min cool down (jogging, stretching) sessions together.

No other technical or tactical training was performed on the training days with SSG, SER and CT during the six-week period. On the other days of the week, training started with warm-up exercises (low-intensity running, dynamic stretching, and short passing) and was followed by technical and tactical sessions in small and large groups, ending with SSGs and games including more players (commonly 8-a-side or 9-a-side game).

Before all field assessments the players went through a 15-minute warm-up session consisting of approximately $8 \mathrm{~min}$ of low intensity running, followed by $4 \mathrm{~min}$ of accelerations and decelerations over 40-60 m and a 3 min dynamic stretching session of the hip extensors, hip flexors, hamstrings, and quad group muscles. On testing days, players were told to report to the pitch or track three hours after having consumed a light meal and to refrain from strenuous physical activity and avoid caffeine consumption eight hours before testing. All the testing sessions were conducted at the same time of day (9:30-11:30 a.m.) to remove the effects of circadian variation on the variables, as suggested by Drust, Waterhouse, Atkinson, Edwards, and Reilly (2005). During the testing and training sessions, the air temperature remained between $18^{\circ}$ and $25^{\circ} \mathrm{C}$ and humidity between $40 \%$ and $47.1 \%$. The test and research programs are presented in Figure 1.

\section{0-30 m sprint tests}

Short-sprint performance was evaluated over $10 \mathrm{~m}$ and $30 \mathrm{~m}$ distances on natural grass fields. Time was recorded using Smartspeed (Fusion Sport Pty Queensland, Australia), with photoelectric cells placed at 0,10 and $30 \mathrm{~m}$ distances to capture measurements at these points. Then, the data recorded were sent to a computer and saved in seconds. As Svensson and Drust (2005) suggested, a $30 \mathrm{~cm}$ head start was given before the start line. Players were given 3 min breaks between three sprints. The best performance out of three trials was further considered.

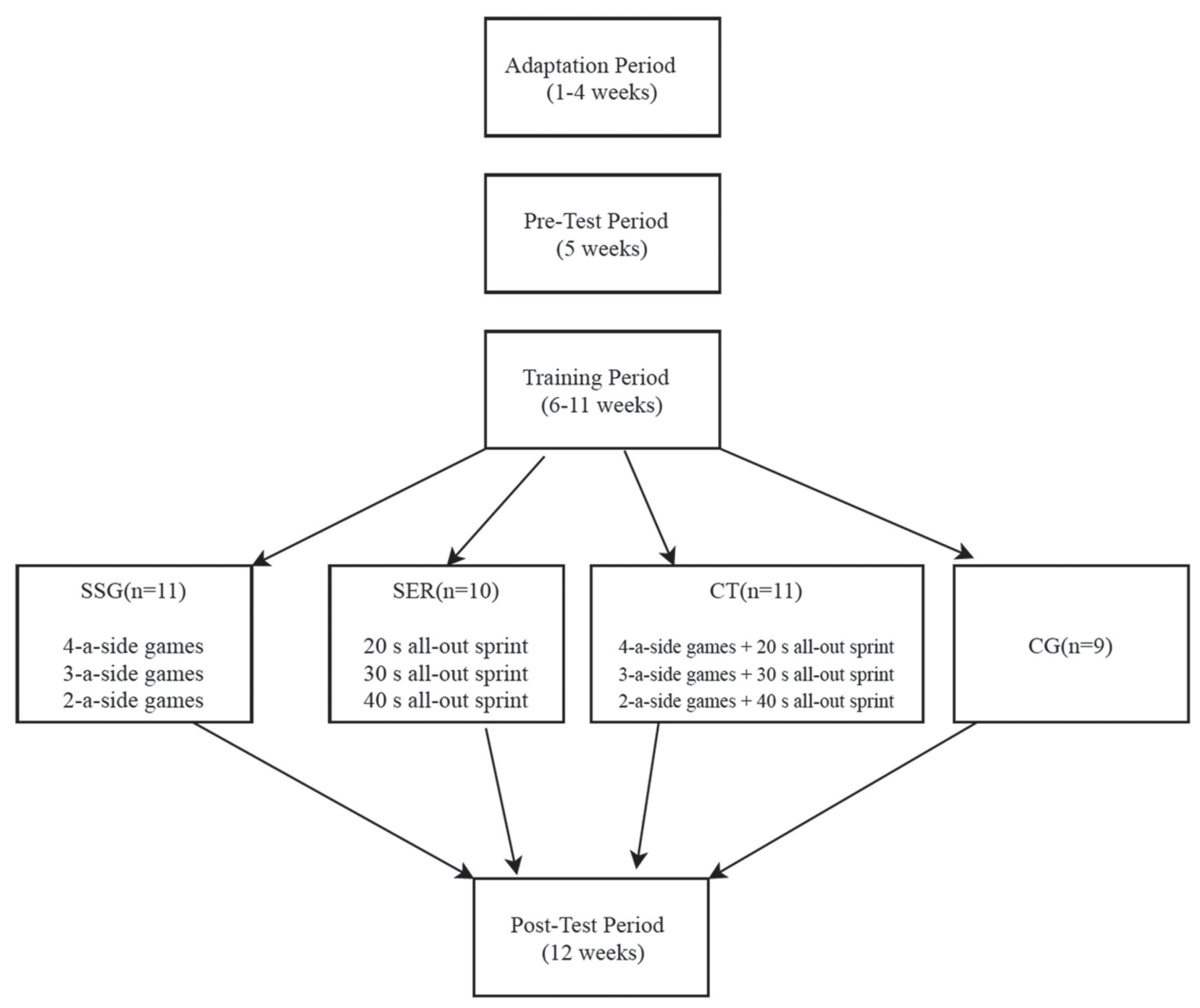

Note. SSG= small-sided game group; $\mathrm{SER}=$ speed endurance running group; $\mathrm{CT}=$ combined training group: $\mathrm{CG}=$ control group .

Figure 1. Schematic representation of the research design. 


\section{Repeated sprint ability test (RSA)}

The $7 \times 35$ m repeated-sprint ability test was conducted on a natural grass field with a 30 -s rest between sprints (Ingebrigtsen, et al., 2013). In the $7 \times 35 \mathrm{~m}$ repeated sprint ability test, the photocell doors of the device (Smartspeed, Fusion Sport Pty Queensland, Australia) were placed at the start line and at the $35 \mathrm{~m}$ line. For every 35 $\mathrm{m}$ sprint, the sprint time was sent to the computer and recorded in seconds. During the repeated-sprint tests, the players started from a standing position with their foot on a marked line $30 \mathrm{~cm}$ behind the first set of photocells, and the timer was initialized when the players broke the beam of the photocell, as suggested by Svensson and Drust (2005). The best sprint time (RSAbest), total sprint time (RSAtotal) and performance decrement (RSAdec) were recorded for analysis.

\section{Yo-Yo intermittent recovery tests (Yo-Yo IR)}

Level 1 and level 2 Yo-Yo IR tests, developed specifically for soccer, were administered on natural grass fields. The Yo-Yo IR1 and Yo-Yo IR2 consist of $2 \times 20 \mathrm{~m}$ shuttle runs, back and forth between the starting, and finishing lines with a turn running speed, which progressively increases, is controlled by audio bleeps from a tape recorder (Krustrup, et al., 2003). The Yo-Yo IR1 started at $10 \mathrm{~km} \cdot \mathrm{h}^{-1}$ and Yo-Yo IR 2 started at $13 \mathrm{~km} \cdot \mathrm{h}^{-1}$. Between each running bout, the participant has a 10 -s rest period (Bangsbo, Iaia, \& Krustrup, 2008). The test result is recorded as the distance covered at the moment the participant has twice failed to reach the finishing line in the allocated time. The tape (Yo-Yo tests, $\mathrm{HO}+$ Strom, Denmark) was calibrated before every trial, and the procedures were identical to those previously described and suggested by Bangsbo et al. ( 2008). The total distance covered by each player during the tests was recorded.

\section{Small-sided games (SSG)}

In the first two weeks, the SSGs were played in an area of $25 \mathrm{~m} \times 32 \mathrm{~m}$ in a 4-a-side format for $4 \times 4$ min. In the 3 rd and 4th weeks, 3-a-side SSGs were played in a $20 \mathrm{~m} \times 30 \mathrm{~m}$ area for $4 \times 4 \mathrm{~min}$, and in the 5th and 6th weeks, 2-a-side games were played in a $16 \mathrm{~m} \times 25 \mathrm{~m}$ area for $4 \times 2$ min periods (Table 2). Three-minute rest periods were given between the bouts. The soccer players were verbally encouraged to exert their maximum effort during the games as described by Rampinini et al. (2007). Extra balls were placed in the goals and all along the line marking the boundary of the pitch to enable the game to be re-started immediately after the ball left the playing area from the place where it left. The SSGs were performed on a natural grass field.

\section{Speed endurance running (SER)}

The speed endurance running training consisted of 6-9 bouts of 20, 30 or 40-s all-out runs interspersed with 100, 150 and 200-s recovery periods between the bouts, respectively (Table 2). Players ran all-out for 20-s in the first two weeks, 30 -s in weeks 3 and 4, and 40-s in weeks 5 and 6 . The running was performed on a natural grass field, and the participants had to perform a $180^{\circ}$ turn every time they reached the edge of the pitch. The players were instructed to run all-out during each bout and were verbally encouraged by the researchers to put in their maximum effort.

Table 2. Training programs

\begin{tabular}{|c|c|c|c|c|c|c|}
\hline & SSG & & SER & & CT & \\
\hline $\begin{array}{l}\text { Week/ } \\
\text { Session }\end{array}$ & Training (s) & $\begin{array}{c}\text { Number } \\
\text { of Bouts/ } \\
\text { Rest (min) }\end{array}$ & Training (s) & $\begin{array}{l}\text { Number } \\
\text { of Bouts/ } \\
\text { Rest (s) }\end{array}$ & Training (s) & $\begin{array}{c}\text { Number } \\
\text { of Bouts/ } \\
\text { Rest (min) }\end{array}$ \\
\hline $1-1$ & 4-a-side game (240s) & $4 / 3$ & 20 s all-out sprint & $7 / 100$ & 4-a-side game $(220 s)+20$ s all-out sprint & $4 / 3$ \\
\hline $1-2$ & 4-a-side game (240s) & $4 / 3$ & 20s all-out sprint & $8 / 100$ & 4-a-side game (220s) + 20s all-out sprint & $4 / 3$ \\
\hline $2-1$ & 4-a-side game (240s) & $4 / 3$ & 20s all-out sprint & $9 / 100$ & 4-a-side game (220s) + 20s all-out sprint & $4 / 3$ \\
\hline $2-2$ & 4-a-side game (240s) & $4 / 3$ & 20s all-out sprint & $9 / 100$ & 4-a-side game (220s) + 20s all-out sprint & $4 / 3$ \\
\hline $3-1$ & 3-a-side game (180s) & $4 / 3$ & 30s all-out sprint & $7 / 150$ & 3-a-side game $(150 s)+30$ s all-out sprint & $4 / 3$ \\
\hline $3-2$ & 3-a-side game (180s) & $4 / 3$ & 30s all-out sprint & $8 / 150$ & 3-a-side game (150s) + 30s all-out sprint & $4 / 3$ \\
\hline $4-1$ & 3-a-side game (180s) & $4 / 3$ & 30s all-out sprint & $8 / 150$ & 3 -a-side game $(150 \mathrm{~s})+30$ s all-out sprint & $4 / 3$ \\
\hline $4-2$ & 3-a-side game (180s) & $4 / 3$ & 30s all-out sprint & $9 / 150$ & 3-a-side game (150s) + 30s all-out sprint & $4 / 3$ \\
\hline $5-1$ & 2-a-side game (120s) & $4 / 3$ & 40s all-out sprint & $6 / 200$ & 2-a-side game (80s) + 40s sprint all-out sprint & $4 / 3$ \\
\hline $5-2$ & 2-a-side game (120s) & $4 / 3$ & 40s all-out sprint & $7 / 200$ & 2-a-side game (80s) + 40s sprint all-out sprint & $4 / 3$ \\
\hline $6-1$ & 2-a-side game (120s) & $4 / 3$ & 40s all-out sprint & $8 / 200$ & 2-a-side game (80s) + 40s sprint all-out sprint & $4 / 3$ \\
\hline $6-2$ & 2-a-side game (120s) & $4 / 3$ & 40s all-out sprint & $9 / 200$ & 2-a-side game (80s) + 40s sprint all-out sprint & $4 / 3$ \\
\hline
\end{tabular}

Note. $S S G=$ small-sided games group; $S E R=$ speed endurance running group; $C T=$ combined training group. 


\section{Combined training (CT)}

In the combined speed endurance training sessions, participants played 4-a-side SSGs on a pitch area $25 \mathrm{~m} \times 32 \mathrm{~m}$ for 4 × 220 -s and performed 20 -s speed endurance runs. In weeks 3 and 4 , participants played 3-a-side SSGs in a $20 \mathrm{~m} \times 30$ $\mathrm{m}$ area for 4 x 150-s and then performed 30 -s speed endurance runs. In weeks 5 and 6 , participants played 2-a-side games in a $16 \mathrm{~m} \times 25 \mathrm{~m}$ area for $4 \times 80$-s periods and then performed 40 -s speed endurance runs. Three-minute resting periods were given between the SSGs bouts. The soccer players were asked to put in the maximum effort during the combined training. As soon as the small-sided games ended, the players performed SERs over a distance of 100-meter on a soccer pitch in which they had to perform a $180^{\circ}$ turn every time when reached the sideline of the pitch. Table 2 shows all the different training protocols performed during the study.

\section{Statistical analyses}

The data collected are reported as means and standard deviations. Before using parametric tests, the assumption of normality was verified using the skewness and kurtosis test. The skewness and

\section{Results}

The pretest data indicated no statistical differences in each dependent variable between the groups $(\mathrm{p}<.05)$. The $t$-test results of the pretestposttest comparisons of the SSG, SER, CT and CG can be seen in Table 3 . The 6-week training caused a statistically significant negative effect on the 10 $\mathrm{m}$ sprint times of all the groups and on the $30 \mathrm{~m}$ sprint times of the CT group ( $<<.05)$. Along with this finding, the training did not have a statistically significant effect on the RSA $\mathrm{best}, \mathrm{RSA}_{\text {total }}$ or RSA values in the $7 \times 35 \mathrm{~m}$ repeated sprint ability test for any of the groups $(p>.05)$. In contrast, the Yo-Yo IR1 performances of all the groups saw a statistically significant improvement in their pretest-posttest comparisons $(\mathrm{p}<.05)$. There was also a statistically significant improvement in Yo-Yo IR2 test performance for all the groups except for the $\mathrm{CG}$ $(\mathrm{p}<.05)$.

According to the obtained ANOVA test results, percentage change of SSG, SER, CT and CG in the Yo-Yo IR1 and Yo-Yo IR2 performances are given in Figure 2. In terms of Yo-Yo IR1 test performance, only the CT training sessions induced a statistically significant improvement when compared to the $\mathrm{CG}(\mathrm{p}<.05)$. In addition, all the three experimental

Table 3. Changes in sprint, repeated sprint, Yo-Yo IRI and Yo-Yo IR2 performance from pre-to post-training for each of the training groups

\begin{tabular}{|c|c|c|c|c|c|c|c|c|}
\hline & \multicolumn{2}{|c|}{ SSG } & \multicolumn{2}{|c|}{ SER } & \multicolumn{2}{|c|}{ CT } & \multicolumn{2}{|c|}{ CG } \\
\hline & Pre-training & Post-training & Pre-training & Post-training & Pre-training & Post-training & Pre-training & Post-training \\
\hline $10 \mathrm{~m}$ sprint test (s) & $1.69 \pm 0.08$ & $1.76 \pm 0.10^{*}$ & $1.67 \pm 0.04$ & $1.78 \pm 0.11^{*}$ & $1.74 \pm 0.11$ & $1.84 \pm 0.07^{\star}$ & $1.74 \pm 0.06$ & $1.84 \pm 0.08^{*}$ \\
\hline $30 \mathrm{~m}$ sprint test (s) & $4.41 \pm 0.25$ & $4.43 \pm 0.22$ & $4.27 \pm 0.13$ & $4.42 \pm 0.14^{\star}$ & $4.50 \pm 0.35$ & $4.53 \pm 0.22$ & $4.49 \pm 0.19$ & $4.51 \pm 0.15$ \\
\hline $7 \times 35$ m BST (s) & $5.21 \pm 0.30$ & $5.17 \pm 0.25$ & $5.02 \pm 0.19$ & $5.03 \pm 0.10$ & $5.15 \pm 0.33$ & $5.14 \pm 0.23$ & $5.24 \pm 0.33$ & $5.22 \pm 0.26$ \\
\hline $7 \times 35$ m TST (s) & $37.64 \pm 2.29$ & $37.41 \pm 1.68$ & $36.34 \pm 1.28$ & $36.49 \pm 0.94$ & $37.12 \pm 2.17$ & $37.30 \pm 1.57$ & $38.68 \pm 2.78$ & $38.59 \pm 1.65$ \\
\hline $7 \times 35$ m PD (\%) & $3.14 \pm 1.25$ & $3.38 \pm 1.30$ & $3.39 \pm 1.25$ & $3.49 \pm 1.24$ & $2.84 \pm 0.98$ & $3.69 \pm 1.21$ & $5.38 \pm 2.22$ & $5.65 \pm 2.53$ \\
\hline Yo-Yo IR1 (m) & $1450 \pm 411$ & $1712 \pm 373^{*}$ & $1416 \pm 427$ & $1748 \pm 504^{*}$ & $1385 \pm 504$ & $1778 \pm 740^{*}$ & $1008 \pm 355$ & $1046 \pm 356^{*}$ \\
\hline Yo-Yo IR2 (m) & $520 \pm 144$ & $756 \pm 193^{*}$ & $520 \pm 93$ & $780 \pm 95^{*}$ & $512 \pm 150$ & $800 \pm 328^{*}$ & $442 \pm 136$ & $446 \pm 160$ \\
\hline
\end{tabular}

Note. * = significant difference from pre-training; SSG = small-sided game group; SER = speed endurance running group; CT = combined training group; $C G=$ control group; TST = total sprint time; BST = best sprint time; PD = performance decrement.

kurtosis scores met the criterion of less than \pm 2 for all the variables. A one-way analysis of variance (ANOVA) was performed on each dependent variable to compare differences between the training groups at the pretest. A paired $t$-test was performed on each dependent variable to compare differences between the pretest and posttest for each training group. ANOVA was performed to calculate percentage differences between the four groups. Where statistically significant mean differences were found, Tukey's post-hoc analyses were used to determine significance. The level of statistical significance was set at $\mathrm{p}<.05$.

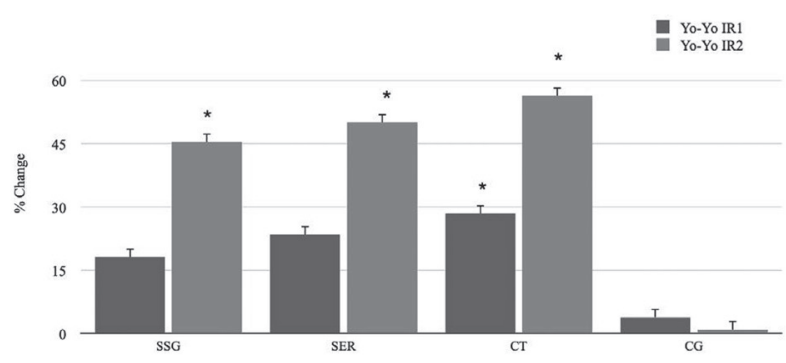

Note. ${ }^{*}=p<.05$. SSG $=$ small-sided game group; SER $=$ speed endurance running group; $\mathrm{CT}=$ combined training group; CG $=$ control group.

Figure 2. Percentage changes in Yo-Yo Intermittent Recovery tests (Level 1 and 2) from pre-to post-training for each of the training groups. 
groups showed a statistically significant improvement of Yo-Yo IR 2 test performance compared to the CG $(p<.05)$. Moreover, there were no significant improvements amongst SSG, SER, CT and CG in $10 \mathrm{~m}$ sprint, $30 \mathrm{~m}$ sprint and $7 \times 35 \mathrm{~m}$ repeated sprint ability tests.

\section{Discussion}

The purpose of this study was to determine the effects of isolated or combined SSG and SER training on sprint, repeated sprint, Yo-Yo IR1 and Yo-Yo IR2 performance in young soccer players. The main finding of the study is that SSG and SER training in isolation or in combination lead to significant improvements in players' Yo-Yo IR1 and Yo-Yo IR2 performances after the training period of six weeks.

The biggest change in pretest-posttest Yo-Yo IR1 performances was observed in the CT (28.4\%), followed by the SER (23.4\%), the SSG (18.1\%) and the CG (3.8\%). As noted above, the improvement shown by the CT is also statistically significant compared to the $\mathrm{CG}(\mathrm{p}<.05)$. The increase in SSG's Yo-Yo IR1 performances provides evidence that SSG drills are suitable for physical endurance training. The positive effects found relating to SER training with respect to Yo-Yo IR1 performance are similar to those found in other studies. For example, Hill-Haas et al. (2009) reported that for the 7-week SSG training and interval running training there were $17 \%$ improvement for the SSG group and 22\% for the interval running training group in Yo-Yo IR1 performance of $14.6 \pm 0.9$ years-old players. In another similar study, Ferrari Bravo et al. (2008) stated that the Yo-Yo IR1 performance increase by $28.1 \%$ for the repeated sprint training and by $12.5 \%$ for high intensity aerobic interval training was a result of a repeated sprint training and high intensity aerobic interval training in $17.3 \pm 0.6$ yearsold players. In addition, the cause of the statistically significant enhancements in the Yo-Yo IR1 distances covered in the CG was thought to be the low-intensity technical and tactical training and the friendly games played.

When the percentage changes in Yo-Yo IR2 pretest-posttest performances are compared, it is seen that the SSG (45.4\%), SER (50.0\%) and CT $(56.3 \%)$ groups displayed a statistically significant enhancement compared to the CG $(0.9 \%)(\mathrm{p}<.05)$. Based on these results, it can be inferred that the training sessions had a positive effect on players' anaerobic endurance performance. In line with the improvement seen in the SER group, Mohr and Krustrup (2016) found that a 4-week (two days per week) speed endurance production training incorporating 30 -seconds of all-out running and 150 -s rests among sets significantly increased Yo-Yo IR2 test performance by $50 \%$, while speed endurance maintenance training (2-a-side SSGs) showed an increase of $26 \%$. In another similar study, Iaia et al. (2015), found that a 3-week (three days per week) speed endurance production training with a 2-min passive rest, 6-8 repetitions and 20-s all-out running induced a $10.1 \%$ increase in Yo-Yo IR 2 performances $(\mathrm{p}<.001)$.

Even though Yo-Yo IR2 performance was significantly improved in all the experimental groups, the training sessions did not have any statistically significant positive effect on $7 \times 35 \mathrm{~m}$ repeated sprint performance (best sprint time and total sprint time). Indeed, the training programs caused a statistically significant decrease in $10 \mathrm{~m}$ sprint times. Therefore, although there was an enhancement in their anaerobic performances, as inferred from the Yo-Yo IR2 performance, this enhancement did not lead to an improvement in acceleration, sprint or repeated sprint performances. The reason for this may be that SSG, SER and CT training programs do not include specific exercises aiming to develop sprinting and repeated sprinting with respect to distance and speed. In a similar study, Hill-Haas et al. (2009) found that a 7-week SSG training (two day per week) did not have any statistically significant effect on $5 \mathrm{~m}$ and $20 \mathrm{~m}$ or RSA sprint performance in $14.6 \pm 0.9$ years-old players. Iaia et al. (2015) also found that a three-week (three days per week) speed endurance production training with 6-8 repetitions, 2 -min passive rest and 20-s of all-out running did not lead to statistically significant improvements in $40 \mathrm{~m}$ sprint, $15 \times 40 \mathrm{~m}$ repeated sprint test performance, or in total repeated sprint test times; in fact, this intervention led to a statistically significant decrease in these performances in $18.5 \pm 1$ yearold players.

There is a limitation of this study-during the training sessions, the distances that were made at different speeds were not tracked with GPS and HR monitoring was not conduced. As a result, changes in external load and internal load which could have been monitored were not.

In conclusion, this stands as the first study to examine the performance effect and training response to combined small-sided games and speed endurance training methods in soccer players. The findings indicate that SSG, SER and CT training can be used for players' aerobic and anaerobic endurance improvement. When the Yo-Yo IR1 and Yo-Yo IR2 pretest-posttest performance changes are considered, the biggest improvement percentage was gained in the CT (percentage change in Yo-Yo IR1 28.4\% and Yo-Yo IR2 56.3\%). In team sports such as soccer, in which the efficient use of training time is important, CT sessions that can cover running drills with and without the ball for the improvement of aerobic and anaerobic endurance are thus recommended to coaches. In addition, this study indicates that SSG, SER and CT training programs do not have positive effects on 
repeated sprint and $10-\mathrm{m}$ and $30-\mathrm{m}$ speed performance. Therefore, in the light of these results, it is recommended that coaches be aware of the fact that training programs that incorporate these three training methods may not have a positive effect on players' speed and repeated sprint performances so other training drills (sprints or repeated sprints) may be needed to improve these attributes. If coaches aim to develop physical performance with a game format, combined training is recommended on the basis of our findings. At the same time, further studies should investigate whether the effects of speed endurance training can be optimized by specific combinations with other types of soccer training.

\section{References}

Ade, J.D., Harley, J.A., \& Bradley, P.S. (2014). Physiological response, time-motion characteristics, and reproducibility of various speed-endurance drills in elite youth soccer players: Small-sided games versus generic running. International Journal of Sports Physiology and Performance, 9(3), 471-479.

Atan, S.A., Foskett, A., \& Ali, A. (2016). Motion analysis of match play in New Zealand U13 to U15 age-group soccer players. Journal of Strength and Conditioning Research, 30(9), 2416-2423.

Bangsbo, J., Iaia, F.M., \& Krustrup, P. (2008). The Yo-Yo intermittent recovery test : A useful tool for evaluation of physical performance in intermittent sports. Sports Medicine, 38(1), 37-51.

Bangsbo, J., Mohr, M., \& Krustrup, P. (2006). Physical and metabolic demands of training and match-play in the elite football player. Journal of Sports Sciences, 24(7), 665-674.

Bishop, D., \& Spencer, M. (2004). Determinants of repeated-sprint ability in well-trained team-sport athletes and endurance-trained athletes. Journal of Sports Medicine and Physical Fitness, 44, 1-7.

Drust, B., Waterhouse, J., Atkinson, G., Edwards, B., \& Reilly, T. (2005). Circadian rhythms in sports performanceAn update. Chronobiology International, 22(1), 21-44.

Dupont, G., Akakpo, K., \& Berthoin, S. (2004). The effect of in-season, high-intensity interval training in soccer players. Journal of Strength and Conditioning Research, 18(3), 584-589.

Faude, O., Steffen, A., Kellmann, M., \& Meyer, T. (2014). The effect of short-term interval training during the competitive season on physical fitness and signs of fatigue: A crossover trial in high-level youth football players. International Journal of Sports Physiology and Performance, 9(6), 936-944.

Ferrari Bravo, D., Impellizzeri, F.M., Rampinini, E., Castagna, C., Bishop, D., \& Wisloff, U. (2008). Sprint vs. interval training in football. International Journal of Sports Medicine, 29(8), 668-674.

Harley, J.A., Barnes, C.A., Portas, M., Lovell, R., Barrett, S., Paul, D., \& Weston, M. (2010). Motion analysis of matchplay in elite U12 to U16 age-group soccer players. Journal of Sports Sciences, 28(13), 1391-1397.

Harrison, C.B., Kilding, A.E., Gill, N.D., \& Kinugasa, T. (2014). Small-sided games for young athletes: Is game specificity influential? Journal of Sports Sciences, 32(4), 336-344.

Hill-Haas, S.V., Coutts, A.J., Rowsell, G.J., \& Dawson, B.T. (2009). Generic versus small-sided game training in soccer. International Journal of Sports Medicine, 30(9), 636-642.

Iaia, F.M., Fiorenza, M., Perri, E., Alberti, G., Millet, G.P., \& Bangsbo, J. (2015). The effect of two speed endurance training regimes on performance of soccer players. PLOS ONE. 10(9), e0138096.

Iaia, F.M., Hellsten, Y., Nielsen, J.J., Fernstrom, M., Sahlin, K., \& Bangsbo, J. (2009). Four weeks of speed endurance training reduces energy expenditure during exercise and maintains muscle oxidative capacity despite a reduction in training volume. Journal of Applied Physiology, 106(1), 73-80.

Impellizzeri, F.M., Marcora, S.M., Castagna, C., Reilly, T., Sassi, A., Iaia, F.M., \& Rampinini, E. (2006). Physiological and performance effects of generic versus specific aerobic training in soccer players. International Journal of Sports Medicine, 27(6), 483-492.

Ingebrigtsen, J., Shalfawi, S.A.I., Tønnessen, E., Krustrup, P., \& Holtermann, A. (2013). Performance effects of 6 weeks of aerobic production training in junior elite soccer players. Journal of Strength and Conditioning Research, 27(7), 1861-1867.

Köklü, Y., Aşçi, A., Koçak, F. Ü., Alemdaroğlu, U., \& Dündar, U. (2011). Comparison of the physiological responses to different small-sided games in elite young soccer players. Journal of Strength and Conditioning Research, 25(6), 1522-1528.

Krustrup, P., Mohr, M., Amstrup, T., Rysgaard, T., Johansen, J., Steensberg, A., Pedersen P.K., \& Bangsbo, J. (2003). The Yo-Yo intermittent recovery test: Physiological response, reliability, and validity. Medicine and Science in Sports and Exercise, 35(4), 697-705.

Los Arcos, A., Vázquez, J.S., Martín, J., Lerga, J., Sánchez, F., Villagra, F., \& Zulueta, J.J. (2015). Effects of smallsided games vs. interval training in aerobic fitness and physical enjoyment in young elite soccer players. $P L o S$ ONE, 10(9), e0137224. 
Mohr, M., \& Krustrup, P. (2016). Comparison between two types of anaerobic speed endurance training in competitive soccer players. Journal of Human Kinetics, 51, 183-192.

Pettersen, S.A., \& Brenn, T. (2019). Activity profiles by position in youth elite soccer players in official matches. Sports Medicine International Open, 3(1), E19-E24.

Radziminski, L., Rompa, P., Barnat, W., Dargiewicz, R., \& Jastrzebski, Z. (2013). A comparison of the physiological and technical effects of high-intensity running and small-sided games in young soccer players. International Journal of Sports Science and Coaching, 8(3), 455-465.

Rampinini, E., Impellizzeri, F.M., Castagna, C., Abt, G., Chamari, K., Sassi, A., \& Marcora, S.M. (2007). Factors influencing physiological responses to small-sided soccer games. Journal of Sports Sciences, 25(6), 659-666.

Rampinini, E., Impellizzeri, F.M., Castagna, C., Coutts, A.J., \& Wisløff, U. (2009). Technical performance during soccer matches of the Italian Serie A league: Effect of fatigue and competitive level. Journal of Science and Medicine in Sport, 12(1), 227-233.

Rebelo, A., Brito, J., Seabra, A., Oliveira, J., \& Krustrup, P. (2014). Physical match performance of youth football players in relation to physical capacity. European Journal of Sport Science, 14(SUPPL.1), 148-156.

Svensson, M., \& Drust, B. (2005). Testing soccer players. Journal of Sports Sciences, 23(6), 601-618.

Thomassen, M., Christensen, P.M., Gunnarsson, T.P., Nybo, L., \& Bangsbo, J. (2010). Effect of 2-wk intensified training and inactivity on muscle $\mathrm{Na}+-\mathrm{K}+$ pump expression, phospholemman (FXYD1) phosphorylation, and performance in soccer players. Journal of Applied Physiology, 108(4), 898-905.

Vigh-Larsen, J.F., Dalgas, U., \& Andersen, T.B. (2018). Position-specific acceleration and deceleration profiles in elite youth and senior soccer players. Journal of Strength and Conditioning Research, 32(4), 1114-1122.

Submitted: Septemeber 24, 2018

Accepted: February 23, 2021

Published Online First: April 15, 2021

Correspondence to:

Yusuf Köklü, Ph.D.

Pamukkale University Faculty of Sport Sciences,

KINIKLI Kampusu, Denizli, Turkey

Phone: +902582961403

Fax: +902582961920

E-mail: ykoklu@pau.edu.tr 